Ege Eğitim Dergisi 2014 (15) 1: 161-175

\title{
Orta Öğretimde Görev Yapan Öğretmenlerin FATíH Projesi’ne İlişkin Görüşleri
}

\author{
Adem ÖZKAN* $\quad$ Demet DENIZ ${ }^{* *}$
}

\section{$\ddot{O} z$}

Bu çalışmanın amac1, Orta Öğretimde görev yapan alan öğretmenlerin Eğitimde FATIH Projesi'nin ana bileşenleri olan donanım ve yazılım altyapısının sağlanması, eğitsel e-içeriğin sağlanması ve yönetilmesi, öğretim programlarında etkin Bilişim Teknolojilerinin kullanımı ve öğretmenlerin hizmet içi eğitime yönelik görüşlerini tespit etmektir. Olgu bilim deseninin kullanıldığı bu çalışmada Ağrı ilindeki pilot okullardan birisi olan Hayrettin Atmaca Anadolu Lisesi'nde 2012-2013 Eğitim- Öğretim yılının bahar döneminde görev yapan 15 öğretmenin görüşleri açık uçlu anket yardımı ile tespit edilmeye çalışılmıştır. Elde edilen veriler içerik analizi ile analiz edilmiş vebu verilerden4 tema-16 kategori- 44kod listesi oluşturulmuştur. Anketlerden elde edilen bulguların sonucunda; bu projede pilot uygulama için gerekli olan BT'nin sağlandığı ancak bu teknolojilerin derslerde kullanılabilmesi için gerekli e-içeriğin olmadığı, öğretmenlere sunulan hizmet içi eğitim sürecinde öğretmenlerin $\mathrm{BT}^{\prime}$ yi kullanma deneyimine yeterince sahip olmadıkları ve dağıtılan tablet bilgisayarların amacına uygun olarak kullanılmadığı görülmüştür. Bu sonuçlara dayanarak;FATİH Projesinin uygulanmasının daha etkili olması için; dağıtılan tablet bilgisayarların içerikleri derslere uygun olarak yapılandırılmalıdır. Ayrıcaöğrencilerin tablet bilgisayarları oyun gibi farklı amaçlarda kullanmaları engellenmelidir. Hizmet içi eğitimleri her okul kendi bünyesinde Bilişim Teknolojileri Öğretmenleri yardımıyla hızlı ve kesin çözüm odaklı olarak yapmaları daha faydalı olabilir.

Anahtar kelimeler: FATïH Projesi, öğretmenler, tablet bilgisayar, etkileşimli tahta, hizmet içi eğitim.

\footnotetext{
* Öğr. Gör., Ağrı İbrahim Çeçen Üniversitesi Meslek Yüksekokulu , aozkan @agri.edu.tr

** Arş.Gör., Ağrı İbrahim Çeçen Üniversitesi Eğitim Fakültesi, ddeniz@agri.edu.tr
} 
The Views of Secondary Education Teachers on FATİH Project

\begin{abstract}
Thepurpose of thestudy is to define theopinions of theteachersabout in-service education, supplying and managing educational e-index, constituting software and hardware basis that constitutes th efundamental complements of FATIH Project in Education. In this study that the figure of phenomelogy was used, the opinions of 15 teachers working in Hayrettin Atmaca Anatolian High School in the academic years of 2012-2013 which is one of the pilot schools in Ağr1 were tried to be detected with the help of open-ended questionnaire. The data that was achieved was analyzed with content analysis and 4 themes, 16 categories and 44 code lists were created by this data. In the results of the findings that were gathered from the questionnaire, it is seen that the information technologies that are necessary for pilot scheme in this region was provide, however there has not beenany e-index in order to use this technology in the courses and the teachers do not own the experience of using IT in the process of in-service educationandalsothe tablet computersthatwerehandedoutcould not be used within the frame of their purpose of usage. According to the seresults, the contents of tablet computers must be configured and made suitable for the courses in order to make the application process of Fatih Project more effective. Inaddition, the use of table ts by students with different saims such as game must be prevented. That each school makes the in-services educations on their own in a fast and certain solution oriented way with the help of Information Technologies Teachers may be much more useful.

Keywords: Fatih Project, teachers, tablet computers, interactiveboards, in-service training.
\end{abstract}




\section{Giriş}

Günümüz dünyasında teknoloji her an değişim içerisindedir. Bu değişim her alanda olduğu gibi eğitim alanında da kendisini göstermektedir. Bilim ve teknolojinin gelişmesiyle geleneksel öğretim yöntemleri bilginin aktarılmasında yetersiz kalmaktadır (Yavuz ve Coşkun, 2008).Bu sonuç doğrultusunda; eğitimde teknoloji destekli öğretim yöntemleri kullanımı önem kazanmaktadır. Ayrıca çağdaş uygarlık seviyesine ulaşmada eğitimde teknoloji kullanmanın katkısı göz ardı edilmemelidir. Ancak ülkemizin şartlarını göz önüne aldı̆̆ımız zaman her bireyin teknolojik imkânlara ulaşmaları mümkün olmayabilir. Ülkemiz; bu imkân eşitsizliğini ortadan kaldırmak için Milli Eğitim Bakanlığı bünyesinde ve Ulaştırma Bakanlığı desteğiyle Fırsatları Artırma ve Teknolojiyi İyileştirme Hareketi (FATİH) Projesini 2010 yılında başlatıp 5 yıl içerisinde tamamlamayı planlamıştır.

Eğitimde FATİH Projesiyle, eğitim ve öğretimde fırsat eşitliğini sağlamak ve okullarımızdaki teknolojiyi iyileştirmek için; okulöncesi, ilköğretim ile ortaöğretim düzeyindeki tüm okullarımızın 570.000 dersliğine LCD Panel Etkileşimli Tahta ve internet ağ altyapısı sağlanacaktır. Aynı zamanda her öğretmene ve her öğrenciye tablet bilgisayar verilecektir. Dersliklere kurulan BT donanımının öğrenme-öğretme sürecinde etkin kullanımını sağlamak amacıyla öğretmenlere hizmet içi eğitimler sunulacaktır. Bu süreçte öğretim programları BT destekli öğretime uyumlu hale getirilerek eğitsel e-İçerikler oluşturulacaktır.

\subsection{Fatih Projesinin Bileşenleri}

Eğitimde FATİH Projesi beş ana bileşenden oluşmaktadır. Bunlar:

1. Donanım ve Yazılım Altyapısının Sağlanması

2. Eğitsel e-İçeriğin Sağlanması ve Yönetilmesi

3. Öğretim Programlarında Etkin BT Kullanımı

4. Öğretmenlerin Hizmet içi Eğitimi

5. Bilinçli, Güvenli, Yönetilebilir ve Ölçülebilir BT Kullanımının sağlanması

\subsubsection{Donanım ve yazılım altyapısının sağlanması.}

Bu kapsamda okulöncesi, ilköğretim ve ortaöğretim düzeyindeki tüm okulların dersliklerine birer adet dizüstü bilgisayar ve projeksiyon cihazı sağlanacaktır. Her okula en az bir adet çok amaçlı fotokopi makinesi, akıllı tahta, doküman kamera ve mikroskop kameranın bulunduğu akıllı bir sınıf oluşturulacaktır. 
Bunların yanında her ilde toplam 110 merkezde uzaktan hizmet-içi eğitim merkezleri kurulacaktır(MEB Eğitim Teknolojileri Genel Müdürlüğü, 2010; akt.: Akgün, Yılmaz ve Seferoğlu, 2011).

\subsubsection{Eğitsel e-içeriğin sağlanması ve yönetilmesi.}

FATIH projesi uygulama planına göre öğretim programlarına uygun ve derslerde yardımcı birer ders materyali olarak kullanılmak üzere elektronik içerikler sağlanacaktır. $\mathrm{Bu}$ e-içeriklerin ses, video, animasyon, sunu, fotoğraf/resim gibi çoklu ortam bileşenleri ile desteklenmiş öğrenme nesnelerinden ve etkileşimli e-kitaplardan oluşması planlanmıştır. Bu eiçeriklere öğretmenler ve öğrenciler web tabanlı ortamlarda hem çevrim-içi hem de çevrim-dışı biçimde kolaylıkla ulaşabilecektir (MEB Eğitim Teknolojileri Genel Müdürlüğü, 2010; akt.: Akgün, Yllmaz ve Seferoğlu, 2011).

\subsection{3. Öğretim programında etkin BT kullanımı.}

Öğretim Programlarının BT kullanımını desteklemesi amacıyla; öğretmen kılavuz kitaplarının okullarımızın dersliklerine sağlanan donanım altyapısı ve eğitsel e-içeriğin etkin kullanımını içerecek şekilde yenilenmesi planlanmıştır (MEB Eğitim Teknolojileri Genel Müdürlüğü, 2010; akt.: Akgün, Yılmaz ve Seferoğlu, 2011).

\subsection{4. Öğretmenlerin hizmet içi eğitimi.}

Projenin bu bileşeni kapsamında; okullarımızda görev yapan yaklaşık 600.000 öğretmenin sınıflara sağlanan donanım altyapısını, eğitsel e-içerikleri ve BT'ye uyumlu hale getirilen öğretmen kılavuz kitaplarını etkin biçimde kullanma becerilerini geliştirmelerine dönük yüz yüze ve uzaktan eğitim aracilığıyla hizmet-içi eğitim faaliyetleri planlanmıştır (MEB Eğitim Teknolojileri Genel Müdürlüğü, 2010; akt.: Akgün, Yılmaz ve Seferoğlu, 2011).

\subsubsection{Bilinçli, güvenli, yönetilebilir ve ölçülebilir BT kullanımının sağlanması.}

$\mathrm{Bu}$ kapsamda her dersliğe geniş bant internet erişimi kablolu bağlantı ile sağlanacaktır. Eğitim-öğretim süreçlerinde BT araçlarıla birlikte internetin de bilinçli ve güvenli kullanımını sağlamak için gerekli donanım ve yazılım altyapısının kurulmasının yanında mevzuat düzenlemesi de yapılacaktır (MEB Eğitim Teknolojileri Genel Müdürlüğü, 2010; akt.: Akgün, Yılmaz ve Seferoğlu, 2011). 


\subsection{Fatih Projesi Pilot Uygulamas1}

Eğitimde FATİH Projesi'nin pilot uygulaması ilk olarak 17 ilimizde 52 okulda uygulanmaya başlanmış ve 2013 Şubat ayında bu 52 okula ek olarak farklı 102 okulun 9.sınıflarına tablet bilgisayar dağıtılarak genişletilmiştir (MEB, 2012). 2013 yılında genişletilen pilot uygulamalar kapsamında Ağrı ili de pilot iller arasına dâhil edilmiştir.

Bu denli önemli bir projenin uygulanabilirliği her ne kadar donanımsal alt yapı hazır olsa bile, proje uygulayıcıları olan ögreticilerin bu projeye yönelik bakış açıları önemlidir. Bu bağlamda yapılan çalışma ile farklı alanlardaki öğretmenlerin bakış açılarının incelenmesi amaçlanmıştır.

\subsection{Araştırmanın Deseni}

\section{Yöntem}

$\mathrm{Bu}$ çalışmada, nitel araştırma yöntemi içerisinde yer alan "olgu bilim" deseni kullanılmıştır. Olgu bilim bireylerin belli bir olguya ilişkin yaşantılarını, bireysel algılarını, bunlara yüklediği anlamları ortaya çıkarmaya çalışan ve genellenebilir sonuçlar ortaya koymayı amaçlamayan bir desendir. Ayrıca bu çalışmalarda genellikle belli bir olguya ilişkin bireysel algıların veya perspektiflerin ortaya çıkarılması ve yorumlanması amaçlanır (Yıldırım ve Şimşek, 2008).

\subsection{Katılımcilar}

Araştırmanın katılımcıları, 2012-2013Eğitim-Öğretim yılının bahar döneminde Ağrı ilindeki Hayrettin Atmaca Anadolu Lisesi'nde görev yapan Matematik, İngilizce, Almanca, Coğrafya, Tarih, Kimya, Biyoloji, Beden Eğitimi, Rehberlik, Din Kültürü ve Ahlak Bilgisi, Türk Dili ve Edebiyatı alanlarından olmak üzere 15 öğretmenden oluşmaktadır.

\subsection{Verilerin Toplanmasi}

$\mathrm{Bu}$ araştırmanın verileri, açık-uçlu sorulardan oluşan bir anket ile elde edilmiştir. Anketteki açık-uçlu sorular, Eğitimde FATİH projesinin dört ana bileşenini olan donanım ve yazılım altyapısının sağlanması, eğitsel e-içeriğin sağlanması ve yönetilmesi, öğretim programlarında etkin BT kullanımı ve öğretmenlerin hizmet içi eğitime ilişkin farklı alanlardaki öğretmen görüşlerini tespit etmeye yönelik olarak hazırlanmıştır. 
2.4. Verilerin Analiz Edilmesi

Açık uçlu soruların yer aldığı anketten elde edilen verilerin analizinde içerik analizi tekniği kullanılmıştır. Elde edilen veriler için tema-kategori-kod listesi oluşturulmuştur. Oluşturulan tema-kategori-kod listesi alan uzmanı olan araştırmacılar tarafından kontrol edilmiştir. Çalışmaya katılan öğretmenlerin görüşlerinden alıntılar yapılırken öğretmenler alanlarının baş harflerine göre kodlanmıştır. Örneğin iki tane İngilizce öğretmeni varsa İ1, İ2; coğrafya öğretmeni C1 şeklindedir.

\section{Bulgular}

Çalışmada 4 tema altında 16 adet kategori ve 44 adet kod oluşturulmuştur. Bu temalar donanım, eğitsel içerik, hizmet içi eğitim ve FATïH Projesi'nin uygulanabilirliğidir.

\subsection{Donanım Teması}

Tablo 1. Donanim temasina ait kategori ve kod tablosu

\begin{tabular}{|c|c|c|c|}
\hline Tema & Kategori & Kod & Açıklama \\
\hline \multirow{5}{*}{$\begin{array}{c}\text { Donanı } \\
\mathrm{m}\end{array}$} & \multirow{3}{*}{$\begin{array}{l}\text { Bilgisayar } \\
\text { Kullanımı } \\
\text { na } \\
\text { yönelik } \\
\text { görüşler }\end{array}$} & $\begin{array}{l}\text { Dikkat } \\
\text { çekme }\end{array}$ & $\begin{array}{l}\text { Bilgisayarın } \\
\text { sunduğu } \\
\text { görseller ile } \\
\text { derse } \\
\text { başlarken } \\
\text { öğrencilerin } \\
\text { dikkatlerini } \\
\text { çekmesi }\end{array}$ \\
\hline & & $\begin{array}{ll}\text { Tekrar } & \text { ve } \\
\text { alıştırma } & \end{array}$ & $\begin{array}{l}\text { Örnek çözme } \\
\text { olanağının } \\
\text { olması }\end{array}$ \\
\hline & & Araştırma & $\begin{array}{l}\text { Ders içerikleri } \\
\text { için gerekli } \\
\text { materyalleri } \\
\text { bulmada }\end{array}$ \\
\hline & \multirow{2}{*}{$\begin{array}{l}\text { Projeksiyo } \\
\mathrm{n} \\
\text { kullanımın } \\
\mathrm{a} \text { yönelik }\end{array}$} & $\begin{array}{l}\text { Dikkat } \\
\text { çekme }\end{array}$ & $\begin{array}{l}\text { Açılamaya } \\
\text { gerek yok }\end{array}$ \\
\hline & & Güdüleme & $\begin{array}{l}\text { Açıklamaya } \\
\text { gerek yok }\end{array}$ \\
\hline
\end{tabular}




\begin{tabular}{|c|c|c|}
\hline \multirow[t]{4}{*}{ görüşler } & $\begin{array}{l}\text { Somutlaştır } \\
\text { ma }\end{array}$ & $\begin{array}{l}\text { Matematik } \\
\text { gibi bazı } \\
\text { derslerde } \\
\text { geometrik } \\
\text { şekillerin ve } \\
\text { soyut } \\
\text { kavramların } \\
\text { modellenmesi } \\
\text { nde } \\
\text { kullanılması }\end{array}$ \\
\hline & \begin{tabular}{l}
\multicolumn{2}{l}{ Kullanilması } \\
nin $\quad$ zor \\
olması
\end{tabular} & $\begin{array}{l}\text { Açılamaya } \\
\text { gerek yok }\end{array}$ \\
\hline & Gereksiz & $\begin{array}{l}\text { Açıklamaya } \\
\text { gerek yok }\end{array}$ \\
\hline & $\begin{array}{l}\text { Tekrar- } \\
\text { alıştırma }\end{array}$ & $\begin{array}{l}\text { Açıklamaya } \\
\text { gerek yok }\end{array}$ \\
\hline \multirow{3}{*}{$\begin{array}{l}\text { Etkileşimli } \\
\text { tahta } \\
\text { kullanımın } \\
\text { a yönelik } \\
\text { düşünceler }\end{array}$} & $\begin{array}{l}\text { Dikkat } \\
\text { çekme }\end{array}$ & $\begin{array}{l}\text { Etkileşimli } \\
\text { tahtanın } \\
\text { sunduğu } \\
\text { görseller ile } \\
\text { derse } \\
\text { başlarken } \\
\text { öğrencilerin } \\
\text { dikkatlerini } \\
\text { çekmesi }\end{array}$ \\
\hline & Güdüleme & $\begin{array}{l}\text { Video ve } \\
\text { görselleri } \\
\text { kullanarak } \\
\text { dersin zevkli } \\
\text { hale } \\
\text { getirilmesi }\end{array}$ \\
\hline & $\begin{array}{l}\text { Zaman alic1 } \\
\text { olması }\end{array}$ & $\begin{array}{l}\text { Açıklamaya } \\
\text { gerek yok }\end{array}$ \\
\hline \multirow{2}{*}{$\begin{array}{l}\text { Tablet } \\
\text { bilgisayar } \\
\text { kullanımın } \\
\text { a yönelik } \\
\text { düşünceler }\end{array}$} & $\begin{array}{l}\text { Öğrenci } \\
\text { takibinin } \\
\text { zorluğu }\end{array}$ & $\begin{array}{l}\text { Sinıf } \\
\text { yönetiminin } \\
\text { zor olması }\end{array}$ \\
\hline & $\begin{array}{l}\text { Sinif } \\
\text { yönetiminin } \\
\text { kolaylığ }\end{array}$ & $\begin{array}{l}\text { Tablet } \\
\text { bilgisayarların } \\
\text { pratik ve eş } \\
\text { zamanlı }\end{array}$ \\
\hline
\end{tabular}




\begin{tabular}{ll}
\hline $\begin{array}{l}\text { Derse uygun } \\
\text { değil }\end{array}$ & Bazı derslerin \\
& kâğg kalem \\
& kullanmadan \\
& işlenmesinin \\
& zor olması \\
\hline Gereksiz & Tablet \\
& bilgisayarların \\
& oyun gibi \\
& farklı \\
& amaçlarla \\
& kullanılması
\end{tabular}

Tablo 1'de görüldüğü gibi bu temanın kategoriler ve kodlarl; bilgisayar kullanımına yönelik düşünceler kategorisinde "dikkat çekme" kodu bilgisayarın sunduğu görseller ile derse başlarken öğrencilerin dikkatlerini çekmede kullanıldığı, "tekrar ve alıştırma" kodu ile bol bol örnek çözme olanağının olduğu, "araştırma" kodu ile ders içerikleri için gerekli materyalleri bulmada faydalanıldığı belirtilmiştir. Projeksiyon kullanımına yönelik düşünceler kategorisinde "dikkat çekme, güdülenme, somutlaştırma, kullanılmasının zor olması, gereksiz, tekrar-alıştırma" kodları yer almaktadır. Bu kodlardan "somutlaştırma" kodu ile matematik gibi bazı derslerde geometrik şekillerin ve soyut kavramların modellenmesinde kullanıldığ belirtilmiştir. Etkileşimli tahta kullanımına yönelik düşünceler kategorisinde bulunan kodlardan; "dikkat çekme" kodu etkileşimli tahtanın sunduğu görseller ile derse başlarken öğrencilerin dikkatlerini çekmede kullanıldığı, "güdüleme" kodu ile video ve görselleri kullanarak dersin zevkli hale getirildiği, zaman alıcı olması kodu ile de etkileşimli tahta kullanmanın çok zaman aldığı belirtilmektedir. Donanım temasındaki diğer bir kategori ise tablet bilgisayar kullanımına yönelik düşüncelerdir. Bu kategorinin kodlarından olan "öğrenci takibinin zorluğu" kodu ile sınıf yönetiminin zor olduğu, "sınıf yönetiminin kolaylı̆̆ı" kodu ile tablet bilgisayarların pratik ve eş zamanlı etkileşimi sağladığı, "derse uygun değil" kodu ile bazı derslerin kâğıt kalem kullanmadan işlenmesinin zor olduğu, "gereksiz" kodu ile de tablet bilgisayarın oyun gibi farklı amaçlarla kullanıldığı belirtilmiştir.Tablet bilgisayarın derslere uygun olmadığını düşünen M1'in açıklamaları şu şekildedir:

“Öğrenci elinde kâğıt kalem olmadan matematik öğrenemez." 
Öğretmenlerin Uzaktan Hizmet İçi Eğitim Deneyimlerinin İncelenmesi 169

Tablet bilgisayarın derslerde kullanımının gereksiz olduğunu düşünen İ2'in açıklamaları şu şekildedir:

"Hiçbir faydası yok. Öğrenciler sadece oyun amaçh kullanıyor. Ders kitabı akıllı tahtada yeterlidir."

\subsection{Eğitsel İçerik Teması}

Tablo 2. Eğitsel içerik temasına ait kategori ve kod tablosu

\begin{tabular}{|c|c|c|c|}
\hline Tema & Kategori & Kod & Açıklama \\
\hline \multirow{8}{*}{ Eğitsel içerik } & \multirow{3}{*}{$\begin{array}{l}\text { E- içeriğin } \\
\text { yeterliliği }\end{array}$} & Yeterli & $\begin{array}{l}\text { Video, slayt vb. } \\
\text { öğelerin eksiklikleri } \\
\text { olması }\end{array}$ \\
\hline & & Kismen yeterli & $\begin{array}{l}\text { Öğrenci düzeyine } \\
\text { ve sınavlarda çıkan } \\
\text { sorulara paralel bir } \\
\text { içeriğin olmaması }\end{array}$ \\
\hline & & Yetersiz & $\begin{array}{l}\text { Açıklamaya gerek } \\
\text { yok }\end{array}$ \\
\hline & \multirow[t]{2}{*}{$\begin{array}{l}\text { E-içeriğe } \\
\text { ulaşmadaki } \\
\text { zorluklar }\end{array}$} & Zorluk yaşıyorum & $\begin{array}{l}\text { Kalitesiz içeriğin } \\
\text { olmasından dolay1 } \\
\text { e-içerik seçiminde } \\
\text { zorluk yaşanması }\end{array}$ \\
\hline & & $\begin{array}{l}\text { Zorluk } \\
\text { yaşamiyorum }\end{array}$ & $\begin{array}{l}\text { Açıklamaya gerek } \\
\text { yok }\end{array}$ \\
\hline & $\begin{array}{l}\text { Ders kitaplarının } \\
\text { bilişim } \\
\text { teknolojilerine } \\
\text { uygunluğu }\end{array}$ & Uygun değil & $\begin{array}{lr}\text { e-içeriğin } & \text { kullanma } \\
\text { zorluğu } & \text { ve e- } \\
\text { içeriğin } & \text { sinav } \\
\text { sistemine } & \text { uygun } \\
\text { olmaması } & \\
\end{array}$ \\
\hline & \multirow{2}{*}{$\begin{array}{l}\text { E-içerik } \\
\text { hazırlamada } \\
\text { kendini yeterli } \\
\text { görme }\end{array}$} & Yeterli & $\begin{array}{l}\text { Öğretmenlerin her } \\
\text { konu için materyal } \\
\text { hazırlayabilmeleri }\end{array}$ \\
\hline & & Kismen yeterli & $\begin{array}{l}\text { Bazı konularda e- } \\
\text { içerik } \\
\text { hazırlayabilme }\end{array}$ \\
\hline
\end{tabular}


Tablo 2'de görüldüğü gibi bu temanın kategorileri ve kodlarına ilişkin; eiçeriğin yeterliliği kategorisinde "yeterli, kısmen yeterli ve yetersiz" kodları vardır. Bu kodlardan "yetersiz" kodu ile video, slayt vb. öğelerin eksiklikleri olduğu, "kısmen yetersiz" kodu ile ise öğrenci düzeyine ve sınavlarda çıkan sorulara paralel bir içeriğin olmadığı belirtilmiştir. E-içeriğe ulaşmada zorluklar yaşama kategorisinde "zorluk yaşıyorum ve zorluk yaşamıyorum" kodları yer almaktadır. Bu kodlardan "zorluk yaşıyorum" kodu ile kalitesiz içeriğin olmasından dolayı e-içerik seçiminde zorluk yaşanması belirtilmiştir. $\mathrm{Bu}$ temada yer alan ders kitaplarının bilişim teknolojilerine uygunluğu kategorisinde ise "uygun değil" kodu ile e-içeriğin kullanma zorluğu ve eiçeriğin sınav sistemine uygun olmadığı belirtilmiştir. E-içerik hazırlamada kendini yeterli görme kategorisinde "yeterli, kısmen yeterli" kodları yer almaktadır. "Yeterli" kodunda öğretmenlerin her konu için materyal hazırlayabildikleri, "kısmen yeterli" kodunda bazı konularda e-içerik hazırlayabildikleri belirtilmiştir. E-içerik hazırlama konusunda kendisini kısmen yeterli gören İ1'in düşünceleri şöyledir:

"Kendim hazırladığım e-içeriklerde konu anlatımı ve alıştırmalar çoğunluktaydı. Ancak öğrencilerin konuyu yeterince içselleştiremediğini düş̈̈nmüyorum. Gramer olarak işe yarasa da diğer alanlarda etkili olmadığın düşünüyorum."

Ders kitaplarının bilişim teknolojilerine uygunluğu kategorisinde "uygun değil" kodu yer almaktadır. Bu kod ile e-içeriğin kullanma zorluğu ve içeriğin sınav sistemine uygun olmadığı belirtilmiştir. 
Öğretmenlerin Uzaktan Hizmet İçi Eğitim Deneyimlerinin İncelenmesi

171

\subsection{Hizmet İçi Eğitim Teması}

Tablo 3. Hizmet içi eğitim temasına ait kategori ve kod tablosu

\begin{tabular}{|c|c|c|c|c|}
\hline Tema & & Kategori & Kod & Açıklama \\
\hline \multirow{9}{*}{$\begin{array}{l}\text { Hizmet } \\
\text { Eğitim }\end{array}$} & & \multirow[t]{3}{*}{ BT kullanma yeterliliği } & Yeterli & Açıklamaya gerek yok \\
\hline & & & Kismen yeterli & Açıklamaya gerek yok \\
\hline & & & Yetersiz & Açıklamaya gerek yok \\
\hline & & \multirow{2}{*}{$\begin{array}{l}\text { BT } \\
\text { konusunda hizmet içi } \\
\text { eğitim gereksinimi }\end{array}$} & $\begin{array}{l}\text { İhtiyaç } \\
\text { duyuyorum }\end{array}$ & $\begin{array}{l}\text { Hizmet içi eğitimin } \\
\text { yetersiz olması }\end{array}$ \\
\hline & İçi & & $\begin{array}{l}\text { İhtiyaç } \\
\text { duymuyorum }\end{array}$ & $\begin{array}{l}\text { BT noktasında sıkınt } \\
\text { yaşanmaması }\end{array}$ \\
\hline & & \multirow{2}{*}{$\begin{array}{l}\text { Etkileşimli tahta } \\
\text { kullanımına yönelik } \\
\text { verilen hizmet içi } \\
\text { eğitimin yeterliliği }\end{array}$} & Yeterli & \\
\hline & & & Yetersiz & $\begin{array}{l}\text { Hizmet içi eğitim } \\
\text { sürecinde uygulama } \\
\text { yapılmaması ve bu } \\
\text { yüzden etkileşiml } \\
\text { tahta kullanmada } \\
\text { sikıntılar yaşanması }\end{array}$ \\
\hline & & \multirow{2}{*}{$\begin{array}{l}\text { FATIHH Projesi ile ilgili } \\
\text { alınan hizmet içi } \\
\text { eğitimin alanla } \\
\text { ilişkilendirilmesi }\end{array}$} & $\begin{array}{l}\text { İlişkilendirebiliy } \\
\text { orum }\end{array}$ & Açıklamaya gerek yok \\
\hline & & & $\begin{array}{l}\text { İlişskilendiremiyo } \\
\text { rum }\end{array}$ & Açıklamaya gerek yok \\
\hline
\end{tabular}

Tablo 3'te görüldüğü gibi bu temanın kategorileri ve kodlarına ilişkin; BT kullanma yeterliliği kategorisi altında "yeterli, kısmen yeterli ve yetersiz" kodları yer almaktadır. BT kullanma konusunda hizmet içi eğitim gereksinimi kategorisi altında bulunan; "ihtiyaç duyuyorum" kodu ile alınan hizmet içi eğitimin yetersiz olduğu, "ihtiyaç duymuyorum" kodu ile ise BT noktasında sıkıntı yaşanmadığı belirtilmiştir. Etkileşimli tahta kullanımına yönelik verilen hizmet içi eğitimin yeterliliği kategorisinde bulunan kodlardan; "yeterli" kodu ile verilen hizmet içi eğitimin yeterli olduğu ve etkileşimli tahta kullanımında zorluk yaşanmadığı, "yetersiz" kodu ile hizmet içi eğitim sürecinde uygulama yapılmadığı ve bu yüzden etkileşimli tahta kullanmada sıkıntılar yaşandığı belirtilmiştir. Bu tema altındaki diğer bir kategori olan FATïH Projesi ile ilgili alınan hizmet içi eğitimin alanla ilişkilendirilmesi kategorisinde "ilişkilendirebiliyorum" ve "ilişkilendiremiyorum" kodları yer almaktadır. 
FATİH Projesi ile ilgili alınan hizmet içi eğitimi alanı ile ilişkilendirebilen M1 katılımcısının düşünceleri şöyledir:

"Her alan öğretmeni kendi içeriğini hazırlayabilecek düzeyde eğitim gördü."

\subsection{FATİH Projesi'nin Uygulanabilirliği Teması}

Tablo 4. FATIH Projesi'nin uygulanabilirliği temasma ait kategori ve kod tablosu

\begin{tabular}{|c|c|c|c|}
\hline Tema & Kategori & Kod & Açıklama \\
\hline \multirow{10}{*}{$\begin{array}{l}\text { FATİH } \\
\text { Projesi'nin } \\
\text { Uygulanabilirliği }\end{array}$} & \multirow[t]{2}{*}{$\begin{array}{l}\text { FATïH Projesi'nin } \\
\text { eğitim için etkin bir } \\
\text { çözüm olması }\end{array}$} & Etkin & $\begin{array}{l}\text { Projenin eğitim için } \\
\text { etkin bir çözüm } \\
\text { olması }\end{array}$ \\
\hline & & Etkin değil & $\begin{array}{lr}\text { Öğrenci } & \text { profiline, } \\
\text { sınav ve } & \text { eğitim } \\
\text { sistemine } & \text { uygun } \\
\text { olmadığ1 } & \text { için } \\
\text { geliştirilmesi } \\
\text { gerekmesi }\end{array}$ \\
\hline & \multirow[t]{3}{*}{$\begin{array}{lr}\text { FATïH } & \text { Projesi'nin } \\
\text { alan için fayda } \\
\text { düzeyi }\end{array}$} & Faydalı & $\begin{array}{l}\text { Dikkat çekme, } \\
\text { pekiştirme ve tekrar } \\
\text { konularında faydalı } \\
\text { olması }\end{array}$ \\
\hline & & Faydasız & $\begin{array}{l}\text { Donanim } \\
\text { eksikliğinin olması }\end{array}$ \\
\hline & & $\begin{array}{l}\text { Kismen } \\
\text { Faydalı }\end{array}$ & $\begin{array}{l}\text { Etkileşimli tahtanın } \\
\text { faydalı ancak tablet } \\
\text { bilgisayarın faydasız } \\
\text { olması }\end{array}$ \\
\hline & \multirow{3}{*}{$\begin{array}{lr}\text { FATïH Projesi'nin } \\
\text { eğitimde } & \text { fırsat } \\
\text { eşitliğinin sağlaması }\end{array}$} & Sağlıyor & $\begin{array}{l}\text { Açılamaya gerek } \\
\text { yok }\end{array}$ \\
\hline & & $\begin{array}{l}\text { Kismen } \\
\text { sağliyor }\end{array}$ & $\begin{array}{lr}\text { Sadece } & \text { bilgisayar } \\
\text { alma } & \text { noktasında } \\
\text { eşitlik sağlaması }\end{array}$ \\
\hline & & Sağlamıyor & $\begin{array}{l}\text { Bilgisayar sahibi } \\
\text { olmamanın artık bir } \\
\text { eşitsizlik olmaması }\end{array}$ \\
\hline & \multirow{2}{*}{$\begin{array}{l}\text { FATIH Projesi'nin } \\
\text { gelecekte }\end{array}$} & Olumlu & $\begin{array}{l}\text { Yapılandırmacı } \\
\text { eğitim sistemine } \\
\text { uygun olması }\end{array}$ \\
\hline & & Olumsuz & Sosyalleşemeyen \\
\hline
\end{tabular}


Tablo 4'te görüldüğü gibi bu temanın kategorileri ve kodlarına ilişkin; FATïH Projesi'nin eğitim için etkin bir çözüm olması kategorisinde bulunan "etkin" kodu ile bu projenin eğitim için etkin bir çözüm olduğu, "etkin değil" kodu ile öğrenci profiline, sınav ve eğitim sistemine uygun olmadığı için geliştirilmesi gerektiği belirtilmiştir. FATïH Projesi'nin alan için fayda düzeyi kategorisi altında "faydalı, faydasız ve kısmen faydalı" kodları yer almaktadır. Bu kodlardan "faydalı" kodu ile dikkat çekme, pekiştirme ve tekrar konularında faydalı olduğu, "faydasız" kodu ile donanım eksikliğinin var olduğunu, "kısmen faydalı" kodu ile ise; etkileşimli tahtanın faydalı ancak tablet bilgisayarın faydasız olduğu belirtilmiştir. Kısmen faydalı olduğunu düşünen İ2 katılımcısının düşünceleri şöyledir:

"Etkileşimli Tahta konusunda gayet etkili ama Tablet Bilgisayar kullanmıyoruz."

FATİH Projesi'nin eğitimde fırsat eşitliğinin sağlaması kategorisi altında bulunan; "sağlıyor" kodu ile eğitimde fırsat eşitliğinin sağlandığı, "kısmen sağlıyor" kodu ile sadece bilgisayar alma noktasında eşitlik sağladığı, "sağlamıyor" kodu ile ise bilgisayar sahibi olmamanın artık bir eşitsizlik olmadığı belirtilmiştir. FATïH Projesi'nin gelecekte uygulanabilirliği kategorisi altında bulunan; "olumlu" kodu ile yapılandırmacı eğitim sisteme uygun olduğu, "olumsuz" kodu ile anti sosyal bireyler yetiştirileceği, okulların kapatılıp uzaktan eğitim yapılacağı ve eğitim sisteminde köklü değişiklikler yapılmadığı takdirde projenin boşa gideceği belirtilmiştir. Bu kategori altında olumsuz düşünce belirten R1 ve İ1katılımcıları sırayla şunları belirtmişlerdir:

“ Daha anti-sosyal bireyler yetiştirmiş olacağız."(R1).

"Gelecekte kişisel bilgisayarlar üzerinden uygulanırsa belki değeri bilinir. Çünkü bedava dağıtılan her şey değersizdir. Ancak çöp olur!" (İ1).

\section{Sonuçlar ve Öneriler}

Anketlerden elde edilen bulguların sonucunda; bu projede pilot uygulama için gerekli olan BT'nin sağlandığı ancak bu teknolojilerin derslerde kullanılabilmesi için gerekli e-içeriğin olmadığı ve sınıf içi kullanımına yönelik düzgün bir planlamanın yapılmadığı görülmüştür. Elde edilen bu sonuçlar Dinçer, Şenkal 
ve Sezgin (2012) ve Akınc1, Kurtoğlu ve Seferoğlu'nun (2012) çalışmasındaki sonuçlarla paralellik göstermektedir.

Ayrıca öğretmenlere sunulan hizmet içi eğitim sürecinde öğretmenlerin BT'yi kullanma becerilerinin yeterince gelişmediği, dağıtılan tablet bilgisayarların amacına uygun olarak kullanılmadığı ve e-içeriğe ulaşmada öğretmenlerin zorluklar yaşadıkları tespit edilmiştir. Elde edilen bu sonuçlar da Akıncı, Kurtoğlu ve Seferoğlu'nun (2012) çalışmasındaki sonuçlarla paralellik göstermektedir.

Bu sonuçlar doğrultusunda; FATïH Projesi'nin daha etkili olması için; dağıtılan tablet bilgisayarların içerikleri derslere uygun olarak yapılandırılmalı ve tablet bilgisayarları öğrencilerin oyun gibi farklı amaçlarla kullanmaları engellenmelidir. Öğretmenlerin e-içeriğe ulaşma noktasında yaşadıkları sorunları gidermek amacıyla; MEB tarafından sadece FATIH Projesi'ne yönelik olarak e-içerik hazırlama birimi kurulabilir. Hizmet içi eğitimleri her okul kendi bünyesinde Bilişim Teknolojileri Öğretmenleri yardımıyla yaptıkları takdirde, hizmet içi eğitim ile ilgili sorunlarına daha kesin ve hızlı çözümler bulabilirler. 


\section{Kaynakça}

Akıncı, A., Kurtoğlu, M. ve Seferoğlu, S. S.(2012). Bir teknoloji politikası olarak fatih projesinin başarılı olması için yapılması gerekenler: bir durum analizi çalışması. Akademik Bilişim 2012, Uşak: Uşak Üniversitesi.

Akgün, E., Yılmaz, E. O. ve Seferoğlu, S. S. (2011). Vizyon 2023 strateji belgesi ve fırsatları artırma ve teknolojiyi iyileştirme hareketi (fatih) projesi: karşılaştırmalı bir inceleme. Akademik Bilişim 2011, Malatya: İnönü Üniversitesi.

Dinçer, S., Şenkal, O. ve Sezgin, M. E. (2012). Fatih Projesi kapsamında öğretmen, öğrenci ve veli koordinasyonu ve bilgisayar okuryazarlık düzeyleri. Akademik Bilişim 2013, Antalya: Akdeniz Üniversitesi.

Yavuz, S. ve Coşkun, A. S. (2008). Sınıf öğretmenliği öğrencilerinin eğitimde teknoloji kullanımına ilişkin tutum ve düşünceleri. Hacettepe Üniversitesi Eğitim Fakültesi Dergisi, 34, 274-286.

Yıldırım, A. ve Şimşek, H. (2008). Sosyal bilimlerde nitel araştırma yöntemleri (7. Baskı) Ankara: Seçkin Yayıncılık. 